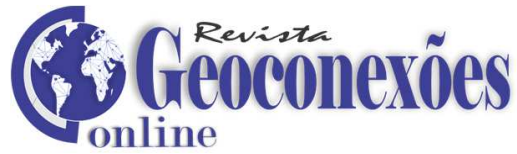

\section{Visitas virtuais a museus durante a pandemia}

\author{
SILVA, Noelma Dutra da ${ }^{1}$ \\ MEDEIROS, Rafael Marrocos ${ }^{2}$
}

\begin{abstract}
Recebido (Received): 17/04/2021 Aceito (Accepted): 25/05/2021
Como citar este artigo: SILVA, N.D.da; MEDEIROS, R.M. Visitas virtuais a museus durante a pandemia. Geoconexões (online), v.1, n.1, p. 73-86, 2021.
\end{abstract}

RESUMO: Por causa do momento atual que a humanidade está passando da pandemia, e levando em consideração nossa nova realidade. $O$ presente trabalho tem como objetivo mostrar como podemos continuar com os trabalhos de campo na disciplina de geografia, mesmo durante a pandemia, com visitas virtuais a museus. Trazendo também as vantagens e desvantagens dessa prática. Trata-se de um trabalho empírico, partindo de nossas próprias experiências como discentes e docentes, um trabalho exploratório bibliográfico e qualitativo. Trabalharemos com três principais referenciais teóricos: Santos (2011), Motta (2020) e Couto et al (2020). O artigo encontra-se dividido em três partes: a primeira trazendo um diálogo com a globalização. A segunda as vantagens que temos ao fazer trabalhos de campo a museus de forma virtual, durante a pandemia. E por último as desvantagens. As vantagens de se realizar um trabalho de campo a um museu de forma virtual no atual momento, sobretudo, é a possibilidade de continuação da prática educativa, do acesso ao lugar (mesmo que de forma remota). Sabendo pois, que não são todos que podem fazer essa atividade, pois o processo de globalização ao mesmo tempo que é inclusiva, se faz também exclusiva.

PALAVRAS CHAVES: Globalização. Pandemia. Trabalho de Campo.

\section{VIRTUAL VISITS TO MUSEUMS DURING THE PANDEMIC}

ABSTRACT: According to the current moment that all of humanity is going through the pandemic, and taking into account our new reality. This work aims to show how we can continue with fieldwork in the discipline of Geography, even during a pandemic, with virtual visits to museums. Also bringing advantages and disadvantages of this practice. It is an empirical work, based on our own experiences as a student and as a teacher, a bibliographic and qualitative exploratory work. We will work with three main authors that will be our theoretical references: Santos (2011), Motta (2020) and Couto et al (2020). The article is divided into three parts: the first one brings a dialogue with globalization. The second one is about the advantages that we have when doing fieldwork to museums in a virtual way, during a pandemic. And the last one talks about the disadvantages. The advantages of conducting fieldwork in a museum online nowadays, specially, is the possibility of continuing the educational practice, of accessing the place (even if in a remotely way). Knowing then that, not everyone can do this activity, since the globalization process, at the same time that it is inclusive, it is also exclusive.

KEY WORDS: Globalization. Pandemic. Fieldwork.

\footnotetext{
${ }^{1}$ Mestranda em geografia cultural (UERJ); licenciada em geografia com ênfase em Meio Ambiente (FEBF/UERJ); cursando bacharel em geografia (UERJ).noelmadutra@gmail.com. Orcid: http://orcid.org/0000-0001-8131-1932

2 Professor da rede privada de ensino no município de Duque de Caxias; licenciado em geografia com ênfase em Meio Ambiente (FEBF/UERJ); cursando bacharel em geografia (UERJ). marrrocos@hotmail.com. Orcid: https://orcid.org/0000-0003-0697-6904
} 


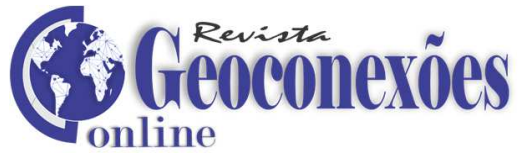

Introdução

Concelho ao Povo

EVITAR aglomerações, principalmente à noite.

NÃO fazer visitas.

TOMAR cuidados higiênicos com o nariz e a garganta

(...).

EVITAR toda fadiga e excessos psicológicos.

O DOENTE aos primeiros sintomas, deve ir para a cama, pois o repouso auxilia a cura e afasta as complicações e contágio. Não se deve receber, absolutamente nenhuma visita.

AS PESSOAS IDOSAS devem aplicar se de mais rigor ainda todos os cuidados.

(Correio da manhã)

Ao se ler a notícia acima, parece que estamos lendo os jornais em meados do mês de março de 2020 quando a pandemia da Covid 19, chegou oficialmente no Brasil. Porém, a notícia se trata de um anúncio de 21 de outubro do ano de 1918 do jornal carioca "Correio da Manhã". Abrimos o artigo com essa informação, pois ficamos todos assustados com a pandemia atual. Porém, ela não foi a primeira. Se voltarmos na história veremos como a famosa "Peste Negra" assolou a Europa durante o século XIV; a varíola que matou gente durante 3 mil anos no mundo todo, só sendo erradicada na segunda metade do século XX; A cólera que sofre variadas mutações e ainda mata, desde 1917 e; a gripe suína (H1N1) que, mesmo não tendo chegado à proporção de morte do novo Coronavírus, se espalhou rapidamente pelo mundo em 2009. Tudo isso foi posto já de início, para sabermos que pandemias já aconteceram e podem acontecer futuramente. Assim, nós que somos profissionais da educação, também como os profissionais da saúde, precisamos estar preparados para as mudanças, sendo preciso nos adaptarmos às novas realidades e continuarmos com o nosso propósito de educador.

O presente trabalho tem como objetivo mostrar as vantagens e desvantagens de visitas virtuais a museus no atual período da pandemia, com um olhar geográfico. Se trata de um trabalho empírico, partindo de nossas próprias experiências de vida como docentes e discentes, sendo um trabalho exploratório bibliográfico e qualitativo. $\mathrm{O}$ artigo se encontra dividido em quatro partes: a primeira trazendo um diálogo com a globalização; segundo as vantagens que temos ao fazer trabalhos de campo a museus de forma virtual, durante a pandemia e por último as desvantagens.

Foi utilizado na pesquisa o trabalho de Motta (2020), que versa em seu artigo intitulado a "Museus históricos no mundo digital e suas potencialidades em sala de aula" de como na

Revista Geoconexões Online, v.1, n.1 (2021), 2021. P.73-86. 


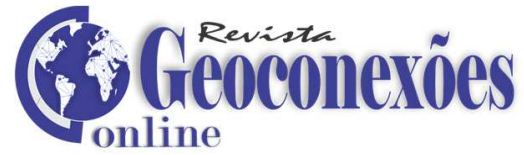

atualidade as tecnologias, podem ser usadas ao nosso favor de forma positiva na construção e difusão do conhecimento. A autora ainda faz a alusão de como o cenário da pandemia nos fez mudar o nosso modo de agir e pensar, nos levando a ver como podemos usar as visitas virtuais a museus como ferramenta metodológica e didática. Tendo em vista que a autora trata sobre o ensino de história em seu trabalho, adaptaremos o trabalho para a Geografia. Utilizou-se também como referência o artigo "\#ficaemcasa: educação na pandemia do covid 19", de autoria de Couto et al (2020). Os autores nos levam a pensar sobre o papel da educação no cenário da pandemia, nos levando à reflexão de como é diferente $o$ isolamento social de quem tem acesso à internet para quem não tem (exclusão digital). Ainda como referência, usufruiu-se do trabalho de Santos (2011), que em seu livro clássico "Por uma outra globalização", nos leva a voltar ao pensamento de como a globalização é, ao mesmo tempo, inclusiva e exclusiva. Tal pensamento pode ser bem observado no momento atual em que estamos vivendo.

\section{Minha casa é maior que o mundo}

Antes mundo era pequeno

Porque terra era grande Hoje mundo é muito grande

Porque terra é pequena(...)

Antes longe era distante

Perto, só quando dava Quando muito, ali defronte

E o horizonte acabava(...)

(Gilberto Gil, Parapolicamará, 1992)

Já dizia o poeta Manoel de Barros "Meu quintal é maior que o mundo". Contemporaneamente, podemos dizer que o mundo todo e mais um pouco cabe na palma de nossa mão. Se "antes o mundo era pequeno, porque terra era grande", sabemos que hoje com o acesso a internet "mundo é muito grande, porque terra é pequena". Se antes para visitar o Museu do Louvre em Paris ${ }^{3}$, o Museu Metropolitan ${ }^{4}$ nos Estados Unidos, ou até mesmo o Museu de Arte $^{5}$ em São Paulo, tínhamos que pegar um navio, um ônibus, um avião ou um carro e ir até eles. Hoje podemos entrar neles, sem sair de nossas casas. Porque "antes era distante, perto só quando dava", perto só quando tínhamos condições financeira e logística.

\footnotetext{
${ }^{3}$ https://www.louvre.fr/

${ }^{4}$ https://www.metmuseum.org/

${ }^{5}$ https://masp.org.br/
} 


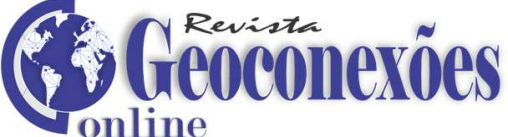

Infelizmente como pudemos vivenciar, com o processo de globalização, não são só as informações que circulam de forma rápida. Tudo tem seu lado positivo e negativo. Vimos um vírus na qual o primeiro caso oficialmente descoberto, apareceu na cidade de Wuhan na China, se espalhar rapidamente por todo o mundo. O desespero tomou conta da população, mostrando o pior e melhor lado dos seres humanos. É evidente que a situação é ainda mais dramática, pois se olharmos os livros didáticos as grandes pandemias que existiram não estão presente em suas páginas. Parece que o assunto precisava ser escondido. Como nos fala Couto et al (2020, p. 202):

\section{Se há escassez de documentação escrita sobre as epidemias, são muitas as representações, em desenhos, pinturas e fotografias, realizadas durante ou depois dos surtos. Imagens de pessoas enfermas, máscaras, hospitais lotados, corpos empilhados e valas comuns dão a sensação de medo da repetição da tragédia e, ao mesmo tempo, a de que aquele cenário faz parte de outro tempo. (COUTO et al, 2020, p. 202).}

No começo da pandemia as tecnologias já estavam disponíveis para serem usadas por nós. Muitos tiveram que aprender de forma forçada a usar algumas ferramentas, como os professores que davam aulas presenciais e tiveram que começar a usar o Youtube, Google Meet, Cybercafe, etc, para dar aulas remotas. As visitas virtuais a museus, também não são nenhuma novidade que tenha surgido durante a pandemia. Contudo, devido à necessidade de afastamento social e a interdição ao acesso de determinados espaços à tecnologia ficou ainda mais presente em nossas vidas. Tivemos que nos adaptar querendo ou não. Sabe-se que o trabalho de campo é essencial na disciplina de Geografia.

Assim sendo, as visitas virtuais à museus é uma ferramenta metodológica e didática essencial, para ser usada atualmente por alunos e professores, dado o momento de pandemia a qual estamos. Segundo Motta (2020, p. 241): "Enquanto elaborador de discursos e instância de comunicação, o museu possui diversas possibilidades de vinculação com a educação formal, fornecendo ao professor ferramentas metodológicas e didáticas muito ricas."

É irrefutável que, diferente de outras pandemias, por causa das tecnologias da informação da atualidade, estamos em vantagens. Agora em pleno século XXI, esse isolamento social, é apenas de corpos, pois podemos nos comunicar uns com os outros em tempo real. Dependendo do nosso emprego, muitos puderam trabalhar em casa, continuar estudando em domicilio e continuar se comunicando com os familiares e amigos de forma online. Além do mais, não temos notícias só do nosso bairro, cidade, estado ou país, temos notícias do mundo todo. Sendo até mais fácil saber notícias internacionais, do que de nosso próprio lugar como bairro. Os museus são também uma forma de nos comunicarmos com o mundo, com o passado, presente e futuro. Vemos neles essa possibilidade de comunicação 


\section{Ge Gieoconerões}

no tempo e no espaço histórico e geográfico. Sobre esse pensamento Santos (2011, p. 4041) completa:

O fato de que a comunicação se tornou possível à escala do planeta, deixando saber instantaneamente o que se passa em qualquer lugar, permitiu que fosse cunhada essa expressão, quando, na verdade, ao contrário do que se dá nas verdadeiras aldeias, é frequentemente mais fácil comunicar com quem está longe do que com o vizinho. Quando essa comunicação se faz, na realidade, ela se dá com a intermediação de objetos. A informação sobre o que acontece não vem da interação entre pessoas, mas do que é veiculado pela mídia, uma interpretação interessada, senão interesseira, dos fatos. (SANTOS, 2011, p. 40-41).

Mesmo que os museus sejam muito usados pelos professores de história e artes, eles possuem grande potencial, para atender a todas disciplinas escolares. E ainda mais a população como um todo, os museus de nossa cidade, de nosso país, do mundo todo, são parte de nossa história e geografia como sociedade. Precisamos nos apropriar deles, de tudo que trazem como simbolismo, memórias e de nossas identidade passadas, presentes e futuras. Ter a tecnologia a nosso favor, nesse sentido é de grande relevância e precisamos aproveitar na educação escolar. Diante de tudo que foi posto, Motta (2020, p. 243) acrescenta:

\footnotetext{
É preciso pensar os museus também enquanto espaços de ciência, de memória, de identidade e de escrita da história, levando em conta a intencionalidade, historicidade, materialidade, apropriação, elaboração de sentidos e simbolismo presentes nesse processo museológico. Por mais que museus históricos enfrentem ainda hoje algumas dificuldades para a realização desse salto interpretativo, além das identificadas anteriormente, eles também vêm buscando se reinventar. Nesse sentido, a tecnologia tem se apresentado como uma ferramenta muito positiva. (MOTTA, 2020, p. 243).
}

Diante de tudo que foi posto, o atual momento delicado que a humanidade atravessa, de acelerações temporais e limitações transitórias, possibilita inúmeras oportunidades de conhecer outros espaços, via web. Sendo assim, se ter a possibilidade de entender outras geografias, povos, gêneros de vida, ou seja, outros saberes de sociedades em espaços longínquos, que podem se tornar familiares ao click de um botão. Logo, colaborando para aprimorar o conhecimento, abrir espaço para o debate com os discentes e criar momento de reflexão sobre os questionamentos que possam surgir.

\section{As vantagens do trabalho de campo virtual a museus}

"Cada lugar tem acesso ao acontecer dos outros"

Revista Geoconexões Online, v.1, n.1 (2021), 2021. P.73-86. 
(Milton Santos)

Contemporaneamente, museus do mundo todo nos dão acesso a suas galerias e obras de arte, de graça e online. É nossa maior oportunidade de cada lugar ter acesso aos conhecimentos de outros lugares, como já disse Milton Santos, na citação acima. Além de podermos usar essa oportunidade para o lazer e divertimento, podemos também olhar para tudo isso com um olhar geográfico e usar para fins da educação geográfica. Mesmo se estivéssemos com a vida normal, museus e aeroportos abertos, muitos de nós não só alunos, mas também professores, não teríamos condições financeiras, ou até tempo de viajar até esses inúmeros museus. Com a pandemia o lema é \#ficaemcasa, isolamento social, porém não precisamos nos isolar completamente de corpo e alma. Podemos nos conectar com o mundo todo, com sua arte e cultura, no tempo e no espaço. Podemos passear livremente, virtualmente pelos museus, sem casto financeiro alto e sem filas, e agora sem correr o risco de contaminação. Como já dizia Santos (2011, p. 113): "Nas condições atuais, o cidadão do lugar pretende instalar-se também como cidadão do mundo."

De modo geral, se pensarmos bem, os museus estão diretamente ligados a educação. No Brasil, na década de 50 houve grande preocupação de ligar museu a educação, com um proposito voltado para o civismo patriótico, (MOTTA, 2020). Ainda segundo a autora (2020, p. 239):

o museu é, assim, uma instituição a serviço da sociedade destinada a salvaguardar o patrimônio humano e natural, entendendo este como o conjunto de bens que plasmam em sua materialidade as histórias, os contextos, as identidades, as expressões e as crenças de um grupo social, e que, por isso, merecem destaque e proteção. É missão do museu, também, zelar pela proteção e pela divulgação das informações presentes e/ou relacionadas a esse patrimônio. (MOTTA, 2020, p. 239)

Uma das maiores vantagens dos trabalhos de campo a museus de forma virtual, como já foi dito, é poder ir a museus de vários estados do Brasil e até de outros países, sem sair de casa, sem "custo financeiro", sem fila, sem falta de tempo. Outra vantagem é que conhecer um museu grande leva tempo, mas virtualmente esse tempo diminui, ou podemos fazer a visita em momentos variados, como exemplo, o Instituído Inhotim ${ }^{6} \mathrm{em}$ Brumadinho, Minas Gerais. O lugar possui mais de 140 hectares, e para conhecer tudo é necessário mais de um dia e disposição física. Ainda tem a questão de o professor sair com uma turma grande, cada aluno tem interesse por algo diferente, mas no trabalho de campo precisam ficar juntos, para não se perderem. No caso online tudo se torna mais democrático e livre. Concordando com Motta (2020, p. 243) "O uso das tecnologias como dispositivo de

\footnotetext{
${ }^{6}$ https://artsandculture.google.com/streetview/inhotim/ugEcCOCZkq1 4A?hl=pt-br\&sv Ing= 44.2188001394141\&sv_lat=20.12396623579023\&sv_h=310\&sv_p=0\&sv_pid=606d8dFawd97EwRBp2oGWQ\&s v_z=1
}

Revista Geoconexões Online, v.1, n.1 (2021), 2021. P.73-86. 


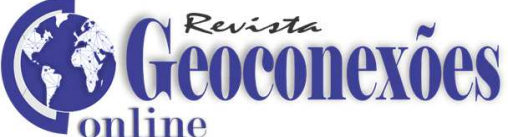

mediação é muito comum e tem ajudado o público na compreensão do espaço expositivo, principalmente quando a temática da exposição impõe desafios de distanciamento temporal, geográfico ou cultural."

Vale ressaltar que além do que já foi dito, existe a questão de poder visitar vários museus, em um curto período de tempo. A pessoa não precisa se deslocar do Louvre em Paris para o Museu Nacional de Antropologia na Cidade do México. Ela faz esse deslocamento virtualmente. "Os últimos anos do século XX testemunharam grandes mudanças em toda a face da Terra. O mundo torna-se unificado - em virtude das novas condições técnicas, bases sólidas para uma ação humana mundializada." (SANTOS, 2011, p. 37). Logo o aluno terá a oportunidade de ver culturas e símbolos de diversos países e épocas históricas. Vai poder viajar no espaço geográfico, como nunca se pode em algumas décadas passadas. Como Santos salienta (2011, p. 31):

O período histórico atual vai permitir o que nenhum outro período ofereceu
ao homem, isto é, a possibilidade de conhecer o planeta extensiva e
aprofundadamente. Isto nunca existiu antes, e deve-se, exatamente, aos
progressos da ciência e da técnica (melhor ainda, aos progressos da
técnica devidos aos progressos da ciência). (SANTOS, 2011, p. 31).

Ademais outra questão é o da inclusão, no caso de alunos com certos tipos de deficiências, como problemas de mobilidade, audição. Esses discentes, terão mais facilidade de percorrer esses museus de suas casas, no seu tempo. Muitos museus oferecem tradução em libras, legendas, facilitando muito a vida deles.

Pensando também na educação básica, levando em consideração o documento da BNCC (Base Nacional Comum Curricular), a visita online virtual a museus, dialoga com o documento, para ser uma proposta aplicada desde os Anos Finais do Ensino Fundamental, com diferentes propósitos. A lista de alguns museus que oferecem este tipo de serviço pode ser encontrada no site: https://www.melhoresdestinos.com.br/museus-virtuais.html.

- No sexto ano, pode-se pedir visitas a museus de diferentes partes do planeta, podese trabalhar conforme a habilidade abaixo (BRASIL, 2018, p. 385):

(EF06GE01) Comparar modificações das paisagens nos lugares de vivência e os usos desses lugares em diferentes tempos.

(EF06GE02) Analisar modificações de paisagens por diferentes tipos de sociedade, com destaque para os povos originários.

- No sétimo ano, pode se pedir visita on-line a diferentes museus em todo o território nacional, para trabalhar com as seguintes habilidades (BRASIL, 2018, p. 387):

(EF07GE01) Avaliar, por meio de exemplos extraídos dos meios de comunicação, ideias e estereótipos acerca das paisagens e da formação territorial do Brasil. 


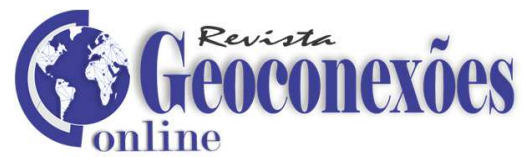

(EF07GE02) Analisar a influência dos fluxos econômicos e populacionais na formação socioeconômica e territorial do Brasil, compreendendo os conflitos e as tensões históricas e contemporâneas.

- No oitavo ano, podemos retornar as visitas a museus on-line por todo o mundo, para ver as seguintes habilidades (BRASIL, 2018, p. 389):

(EF08GE05) Aplicar os conceitos de Estado, nação, território, governo e país para o entendimento de conflitos e tensões na contemporaneidade, com destaque para as situações geopolíticas na América e na África e suas múltiplas regionalizações a partir do pós-guerra.

- E no nono ano, trabalhar com museus internacionais, brasileiros e principalmente europeus, conforme as habilidades a seguir (BRASIL, 2018, p. 393):

(EF09GE01) Analisar criticamente de que forma a hegemonia europeia foi exercida em várias regiões do planeta, notadamente em situações de conflito, intervenções militares e/ou influência cultural em diferentes tempos e lugares.

(EF09GE03) Identificar diferentes manifestações culturais de minorias étnicas como forma de compreender a multiplicidade cultural na escala mundial, defendendo o princípio do respeito às diferenças. (EF09GE04) Relacionar diferenças de paisagens aos modos de viver de diferentes povos na Europa, Ásia e Oceania, valorizando identidades e interculturalidades regionais.

(EF09GE05) Analisar fatos e situações para compreender a integração mundial (econômica, política e cultural), comparando as diferentes interpretações: globalização e mundialização.

E ainda em todas as séries dos Anos Finais do Ensino Fundamental, os alunos vão poder pensar o espaço geograficamente. A relação dos lugares a qual eles vivem, com o resto do mundo. É inegável, que não será a mesma coisa de estar nos museus presencialmente, mas é um modo de trazer o mundo até eles, o conhecimento de outros lugares, outras culturas, outros tempos. Trazer também a curiosidade para que por si só, eles venham buscar adquirir mais conhecimentos. E acima de tudo, vão aprender a pensar criticamente a geografia e suas próprias existências. Conforme nos fala Santos (2011, p. 116):

Nesse processo, afirma-se, também, segundo novos moldes, a antiga oposição entre o mundo e o lugar. A informação mundializada permite a visão, mesmo em flashes, de ocorrências distantes. O conhecimento de outros lugares, mesmo superficial e incompleto, aguça a curiosidade. Ele é certamente um subproduto de uma informação geral enviesada, mas, se for ajudado por um conhecimento sistêmico do acontecer global, autoriza a visão da história como uma situação e um processo, ambos críticos. Depois, o problema crucial é: como passar de uma situação crítica a uma visão 


\section{G. Geoconeroúes}

crítica - e, em seguida, alcançar uma tomada de consciência. Para isso, é fundamental viver a própria existência como algo de unitário e verdadeiro, mas também como um paradoxo: obedecer para subsistir e resistir para poder pensar o futuro. Então a existência é produtora de sua própria pedagogia. (SANTOS, 2011, p. 116).

A possibilidade de conhecer museus em lugares longínquos, em outros estados, regiões e países é uma forma de atividade que deve ser dada como contínua e incorporada como uma nova metodologia de ensino, é a forma mais acessível para que os discentes tenham contato levando em consideração fatores como logística e gastos financeiro, facilitada pelas vantagens de acesso aos conhecimentos mundo pelo canal da web. Conforme defende Motta (2020, p.11): "Um planejamento prévio deve levar em conta também os objetivos traçados, o tempo disponível, os recursos e o público (os alunos e suas especificidades), sem que, com isso, perca unidade, coesão, continuidade, flexibilidade, precisão e clareza."

Com a adoção de planejamentos, um trabalho de campo a um museu via web é possível ser executado nos diferentes segmentos do ensino de acordo com a proposta de documento da BNCC, citando Coutto et at (2020, p.10): "o nosso isolamento social, marcado por essas experiências ciberculturais, para enfrentar a Pandemia da Covid-19, pode ser um isolamento criativo".

Logo, trabalhos de campo a museus é uma possibilidade concreta, a tecnologia favorece, contribui para que o conhecimento em outros espaços e tempos sejam acessados, por meio da tela de algum dispositivo telemático. É possível projetar exposições, conhecer gêneros de vida, sem tantas despesas e com a certeza de que não está correndo risco de ser contaminado ou se tornar um vetor de transmissão da Covid-19.

\section{As desvantagens do trabalho de campo virtual}

"A globalização mata a noção de solidariedade, devolve o homem à condição primitiva do cada um por si e, como se voltássemos a ser animais da selva, reduz as noções de moralidade pública e particular a um quase nada."

(Milton Santos)

A pandemia de SARS-Cov 2 (Covid-19) aprofundou uma realidade já vivenciada por uma grande parte da população brasileira, as dificuldades expostas revelaram como a nossa sociedade é desigual. Isso ficou comprovado com as inúmeras tentativas de realização de aulas através de equipamentos de informática (smartphones, tablets, computadores) via sinal de internet, condição essa que não alcançou o resultado desejado. Nós como profissionais da educação, sabemos que a realidade não é a mesma para todos. E devemos pensar nisso também. Santos (2011, p. 41) completa: 


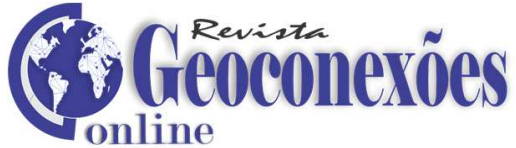

Um outro mito é o do espaço e do tempo contraídos, graças, outra vez, aos prodígios da velocidade. Só que a velocidade apenas está ao alcance de um número limitado de pessoas, de tal forma que, segundo as possibilidades de cada um, as distâncias têm significações e efeitos diversos e o uso do mesmo relógio não permite igual economia do tempo. (SANTOS, 2011, p. 41).

O acesso a equipamentos como computadores e aparelho de celular ainda é um investimento denso para a maior parte das famílias brasileiras, os preços de equipamentos telemáticos são caros se comparado com os rendimentos per capta. Logo nem todos os estudantes e até mesmo professores, sejam da rede pública e em alguns caso também da rede privada tiveram a oportunidade de acompanhar de forma regular os conteúdos ministrados em aula a distância, evidenciando e aprofundando a exclusão digital evidente no Brasil. Isso nos leva ao que Santos (2011) escreveu, uma globalização como fabula e uma como perversidade, ou seja, os acessos as tecnologias da informação são para poucos e para aqueles que podem custear, quanto a maior parte da população e dos estudantes ficou restrita quando não impedida de acessar a informação. Conforme Santos diz (2011, p. 19):

Um mercado avassalador dito global é apresentado como capaz de homogeneizar o planeta quando, na verdade, as diferenças locais são aprofundadas. Há uma busca de uniformidade, ao serviço dos atores hegemônicos, mas o mundo se torna menos unido, tornando mais distante o sonho de uma cidadania verdadeiramente universal. (SANTOS, 2011, p. 19).

Outro ponto que merece destaque, são que nem todos os museus, conseguem oferecer esse tipo de serviço, de visitas online. De certa forma estão também excluídos desse processo de globalização. Durante a pandemia, não puderam abrir para visitas presenciais. E também, não tiveram ferramentas, para oferecer visitas on-line. O professor se encontrará numa situação, que poderá indicar visita on-line a museus de outros países, e não terá essa opção para um museu na cidade que a escola está inserida. Quando Santos (2011, p. 25) escreveu "Na história da humanidade é a primeira vez que tal conjunto de técnicas envolve o planeta como um todo e faz sentir, instantaneamente, sua presença. Isso, aliás, contamina a forma de existência das outras técnicas, mais atrasadas." Parece que estava falando dos tempos de hoje, durante o período da pandemia. Pois foi nesse período que a técnica separou, excluiu, mais ainda, quem estava inserido no processo de globalização e não. Não houve aviso prévio, todos nós fomos pegos desprevenidos. Separando quem já estava inserido completamente nesse meio técnico cientifico informacional, de quem não estava. Santos (2011, p. 83-84) ainda acrescenta:

Hoje, vivemos um mundo da rapidez e da fluidez. Trata-se de uma fluidez virtual, possível pela presença dos novos sistemas técnicos, sobretudo os sistemas da informação, e de uma fluidez efetiva, realizada quando essa fluidez potencial é utilizada no exercício da ação, pelas empresas e instituições hegemônicas. A fluidez potencial aparece no imaginário e na

Revista Geoconexões Online, v.1, n.1 (2021), 2021. P.73-86. 


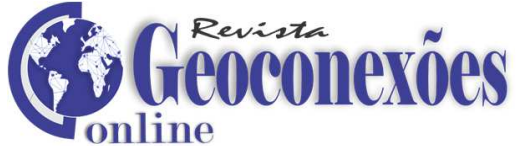

ideologia como se fosse um bem comum, uma fluidez para todos, quando, na verdade, apenas alguns agentes têm a possibilidade de utiliza-la, tornando-se, desse modo, os detentores efetivos da velocidade. O exercício desta é, pois, o resultado da disponibilidades materiais e técnicas existentes e das possibilidades de ação. Assim, o mundo da rapidez e da fluidez somente se entende a partir de um processo conjunto no qual participam de um lado as técnicas atuais e, de outro, a política atual, sendo que esta é empreendida tanto pelas instituições públicas, nacionais, intranacionais e internacionais, como pelas empresas privadas. (SANTOS, 2011, p. 83-84).

E mesmo os alunos e professores que tem acesso à internet, muitos não tem acesso a um bom serviço, pois moram em bairros que esse tipo de serviço é precário, ou é oferecido só por milicianos, como acompanhamos nos noticiários nos últimos meses "Traficantes e milicianos estão interrompendo o serviço de internet de moradores e assumindo o controle da distribuição de sinal em várias regiões do Rio de Janeiro." Sendo assim, não conseguem acessar todos tipos de serviço oferecidos online, como a visita virtual a museus. Como sempre as classes populares, estão sempre vivendo as margens da sociedade, sendo esquecidos pelo poder público, tendo que pegar as migalhas, não podendo escolher os melhores serviços. Como Santos completa: "Há, todavia, sempre, uma seletividade nessa difusão, separando os espaços da pressa daqueles outros propícios à lentidão, e dessa forma acrescentando ao processo de compartimentação nexos verticais que se superpõem à compartimentação horizontal, característica da história humana até data recente." (2011, p. 84). Há de certa forma uma seleção de quem terá os melhores serviços, a qual classe social será oferecido o maior acesso a diversidade cultural. De certa modo, tudo isso sempre foi pensado e proposital. Como discorre Santos (2011, p. 142-143):

Para a maior parte da humanidade, o processo de globalização acaba tendo, direta ou indiretamente, influência sobre todos os aspectos da existência: a vida econômica, a vida cultural, as relações interpessoais e a própria subjetividade. Ele não se verifica de modo homogêneo, tanto em extensão quanto em profundidade, e o próprio fato de que seja criador de escassez é um dos motivos da impossibilidade da homogeneização. Os indivíduos não são igualmente atingidos por esse fenômeno, cuja difusão encontra obstáculos na diversidade das pessoas e na diversidade dos lugares. Na realidade, a globalização a heterogeneidade, dando-lhe mesmo um caráter ainda mais estrutural. (SANTOS, 2011, p. 142-143).

A visita online a museus também nos priva de viver completamente o lugar. Pois numa visita presencial aos museus, nós podemos vivenciar aquele momento de forma completa, com a visão, vendo cada paisagem. Com o tato, sentindo os objetos (quando existe essa possibilidade de interação no museu). Com o olfato, sentindo os cheiros. Com a audição,

\footnotetext{
${ }^{7}$ Disponível em: https://g1.globo.com/rj/rio-de-janeiro/noticia/2020/10/20/traficantes-e-milicianos-cortaminternet-de-moradores-no-rj-para-cobrar-pelo-servico.ghtml
}

Revista Geoconexões Online, v.1, n.1 (2021), 2021. P.73-86. 


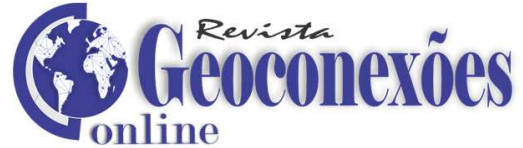

ouvindo cada som. E até com o paladar, comendo comidas típicas daquele lugar. Numa visita on-line, poderemos ter apenas a visão e por vezes a audição.

Por conseguinte, estamos vivendo uma situação atípica, com pessoas desfrutando os benefícios da globalização e outros sendo cada vez mais deixados de lados, visitas a museus presenciais, impossível no momento, pois valorizamos em primeiro lugar a vida e queremos alunos e professores com saúde. Cabe ao professor, nessa situação ver um modo de incluir esse aluno de certa forma no mundo atual, vendo as possibilidades, viáveis, como gravar um vídeo em CD e mandar para ele assistir em DVD, tirar fotos e escrever texto e enviar. Enfim, as possibilidades também são inúmeras. Como Santos disse: "Miseráveis são os que se confessam derrotados. Mas os pobres não se entregam. Eles descobrem cada dia formas inéditas de trabalho e de luta. Assim, eles enfrentam e buscam remédio para suas dificuldades." (2011, p. 132).

\section{Considerações finais}

O mundo é um conjunto indissociável, solidário e também contraditório (SANTOS, 1997). É um espaço repleto de produções, de possibilidades, mas não é feito para todos, por uma questão política. A possibilidade de acesso ao conhecimento pode e deveria ser universal, existem as técnicas e os meios para isso. Visitar um museu de forma remota em um período de pandemia é uma maneira de continuar o processo de educação, de "ir" ao campo de forma segura e não ser um vetor de Covid-19 e de conhecer outros gêneros de vida, outras formas de produção material e imaterial, um outro idioma. O Mundo é único, os lugares são diversos e são representações das manifestações humanas, essenciais para serem vistos na disciplina de geografia.

Diante do que a pandemia provoca, por algum tempo ainda seremos forçados a um afastamento social, contudo a prática educativa não pode ser cessada, as dificuldades são muitas e diversas, apesar da popularização dos instrumentos para telecomunicações, obter um celular, computador, ainda pode ser um investimento de elevado custo, podendo levar ao prejuízo o aprendizado, o conhecimento, o acesso aos conhecimentos fora da sala.

As vantagens de se realizar um trabalho de campo a um museu de forma on-line no atual momento, sobretudo, é a possibilidade de continuação da pratica educativa, do acesso ao lugar (mesmo que de forma remota), do acesso ao conhecimento, da possibilidade de ver, observar, despertar curiosidades sobre outros espaços, sobre outros gêneros de vida e práticas culturais. Tudo dentro de uma relativa segurança com a adoção do afastamento social e dos sistemas técnicos de informação. 


\section{Ge Geecoconexões}

As desvantagens são respondidas com a incapacidade que muitas das escolas (especialmente as públicas) possam ter de planejar e executar um trabalho desse porte, ao menos no Brasil. Devido às desigualdades econômicas, pois muitas escolas não possuem os meios técnicos informacionais necessários para a execução de um trabalho de campo de forma on-line, isso produz um abismo na aprendizagem, nesse ponto, o afastamento social e a restrição aos museus são fatores negativos.

Portanto, o nosso trabalho visa contribuir para gerar reflexão ao leitor, possibilitar discussões que enriqueçam 0 debate e que construam novas perspectivas sobre 0 planejamento e a execução de trabalho de campo a museus através dos sistemas telemáticos. O desafio é enorme, as preocupações são inúmeras, as dúvidas são diversas, contudo a experiência de executar uma atividade como essa é poder observar no rosto de cada aluno e aluna a satisfação por ter tido a oportunidade, talvez inédita de ter contato com outro lugar.

\section{Referências}

BRASIL. Base Nacional Comum Curricular: Educação Infantil, Ensino Fundamental e Ensino Médio. Brasília: MEC/Secretaria de Educação Básica, 2018.

COUTO, Edvaldo Souza. COUTO, Edilece Souza e CRUZ, Ingrid Magalhães Porto. \#ficaemcasa: educação na pandemia da covid 19. Revista Interfaces cientificas. Aracaju. V.8 N.3 - 2020 - Fluxo Contínuo. Disponível em: <https://periodicos.set.edu.br/educacao/article/view/8777 >. Acesso em: 13 fev. 2021. https://doi.org/10.17564/2316-3828.2020v8n3p200-217

Instituído Inhotim em Brumadinho. Disponível em: https://artsandculture.google.com/partner/inhotim?hl=pt-br. Acesso em 20 mar. 2021.

MOTTA, Ana Gláucia Oliveira. Museus históricos no mundo digital e suas potencialidades em sala de aula. Aedos, Porto Alegre, v. 12, n. 26, ago. 2020. Disponível em: < https://seer.ufrgs.br/aedos/article/view/104139>. Acesso em: 13 fev. 2021.

Museu de Arte em São Paulo. Disponível em: https://masp.org.br/. Acesso em: 13 fev. 2021. Museu do Louvre. Disponível em: https://www.louvre.fr/. Acesso em: 20 mar. 2021.

Museu Metropolitan. Disponível em: https://www.metmuseum.org/. Acesso em: 20 mar. 2021.

Museus que oferecem visitas virtuais. Disponível em: https://www.melhoresdestinos.com.br/museus-virtuais.html. Acesso em: 20 mar. 2021.

Reportagem sobre a gripe espanhola. Disponível em: < https://www.brasildefato.com.br/2020/05/01/os-remedios-e-a-historia> Acesso em: 15 fev. 2021. 
Reportagem sobre acesso de internet interrompido e oferecido por milicianos no Rio de Janeiro. Disponível em: https://g1.globo.com/ri/rio-de-janeiro/noticia/2020/10/20/traficantese-milicianos-cortam-internet-de-moradores-no-ri-para-cobrar-pelo-servico.ghtml. Acesso em: 18 fev. 2021.

SANTOS, Milton. A natureza do Espaço: técnica e tempo, razão e emoção.2 ed. São Paulo, Heucitec, 1997.

SANTOS, Milton. Por uma outra globalização: do pensamento único a consciência universal. Rio de Janeiro: Record. 20ํed., 2011. 